\title{
Population-Based Standing Orders: a Novel Approach to Hepatitis C Screening
}

J Gen Intern Med 36(2):538-9

DOI: $10.1007 /$ s11606-020-06123-3

(C) Society of General Internal Medicine 2020

\section{INTRODUCTION}

An estimated 4 million people in the USA have been infected with hepatitis C virus (HCV). ${ }^{1} \mathrm{Up}$ to $75 \%$ of people with HCV were born between 1945 and 1965, leading the CDC and USPSTF to recommend universal one-time HCV screening for this birth cohort. ${ }^{1}$ Several studies have investigated methods to increase $\mathrm{HCV}$ screening rates such as physician-targeted education, electronic medical record (EMR) reminders, and EMRembedded best practice alerts (BPAs), which alert clinicians to current guidelines and facilitates $\mathrm{HCV}$ antibody testing. ${ }^{2-5}$ However, HCV screening rates remain low. ${ }^{2-}$ ${ }^{5}$ With the USA migrating from primarily fee-for-service to more value-based reimbursement models, payors are tying reimbursement to outcomes such as $\mathrm{HCV}$ screening and treatment. ${ }^{6}$

In this study, we conducted a quasi-experimental prepost controlled trial and implemented a novel initiative of population-based bulk standing orders for $\mathrm{HCV}$ screening.

\section{METHODS}

After partnering with the laboratory on creation of a HCV antibody test with reflex to RNA PCR, a database of eligible patients was created for two separate resident academic internal medicine practices at Yale New Haven Hospital (one with intervention and the other without). These practices have relatively similar provider/ patient demographics (Table 1). Both practices use an Epic-based EMR system (Epic Systems Corporation, Verona, WI), each with over 14,000 patient visits per year. Patients were eligible for inclusion if they (1) were born between 1945 and 1965, (2) lacked a prior diagnosis of HCV infection, (3) lacked prior documented anti-HCV testing, and (4) were active with our clinic in the last 2 years.

Received August 4, 2019

Accepted August 7, 2020

Published online August 31, 2020
Using the birth cohort database created, a one-time bulk population level standing order was placed, independent of a patient-provider interaction. The laboratory would automatically draw the blood during the 3-month trial window (alone or in addition to other laboratory tests). Providers were notified of the screening via EMR documentation and messaging. Patients were notified of the test order via mail and EMR messaging (opt-out in nature). Patients were notified of results and positive cases were linked to care. Data were abstracted from the EMR for 3 periods: December 1, 2016-November 31, 2017 (pre-intervention), December 1, 2017-March 1, 2018 (3-month trial period), and March 1, 2018-May 1, 2018 (post-intervention). Data abstraction included age, sex, race, zip code, insurance status, and HCV testingrelated data. The primary outcome was the rate of HCV antibody testing for eligible patients per month.

All analyses were performed with SAS software (version 9.4; SAS Institute, Cary, NC). Distribution of demographic characteristics was compared between the two sites using standardized difference. An interrupted time-series analysis was performed to examine change in $\mathrm{HCV}$ screening rates over time.

\section{RESULTS}

In the 12 months prior to the intervention, the $\mathrm{HCV}$ screening rate was $3.08 \%$ at the intervention site and $3.53 \%$ at the control site, without significant month-tomonth change in overall screening rates between the sites $(p=0.66)$. Immediately following the intervention, the screening rate at the intervention site significantly increased by $6.69 \%(p<0.0001)$, while the change remained insignificant at the control site. Following the intervention, there was a significant decreased month-tomonth trend at the intervention site $(p<0.001)$, while the change remained insignificant at the control site (Fig. 1). Viral PCR seroprevalence in the intervention group during the trial period was $6.67 \%$.

\section{CONCLUSIONS}

Introduction and implementation of a population-based standing orders initiative led to a significant increase in $\mathrm{HCV}$ testing among the birth cohort. The initiative serves as a model for 
Table 1 Demographics

\begin{tabular}{|c|c|c|c|c|}
\hline & \multicolumn{2}{|l|}{ Encounter department } & \multirow[b]{2}{*}{ Total $(N=10933)$} & \multirow[b]{2}{*}{ Standardized difference } \\
\hline & Control site $(N=5462)$ & Intervention site $(N=5471)$ & & \\
\hline \multicolumn{5}{|l|}{ Sex } \\
\hline Female & $3021(55.3 \%)$ & $3636(66.5 \%)$ & $6657(60.9 \%)$ & \multirow[t]{3}{*}{0.23} \\
\hline Male & $2441(44.7 \%)$ & $1835(33.5 \%)$ & $4276(39.1 \%)$ & \\
\hline \multicolumn{4}{|l|}{ Race } & \\
\hline Asian & $55(1.3 \%)$ & $78(2.0 \%)$ & $133(1.6 \%)$ & \multirow[t]{5}{*}{0.26} \\
\hline Black or African American & $2522(59.3 \%)$ & $2275(57.5 \%)$ & $4797(58.4 \%)$ & \\
\hline White or Caucasian & $1674(39.4 \%)$ & $1606(40.6 \%)$ & $3280(40.0 \%)$ & \\
\hline Unknown/missing & 1211 & 1512 & 2723 & \\
\hline \multicolumn{4}{|l|}{ Primary payor } & \\
\hline Commercial & $656(12.0 \%)$ & $507(09.3 \%)$ & $1163(10.6 \%)$ & \multirow{6}{*}{0.16} \\
\hline Managed Medicare & $587(10.7 \%)$ & $464(08.5 \%)$ & $1051(09.6 \%)$ & \\
\hline Medicaid & $2321(42.5 \%)$ & $2329(42.6 \%)$ & $4650(42.5 \%)$ & \\
\hline Medicare A/B & $1235(22.6 \%)$ & $1534(28.0 \%)$ & $2769(25.3 \%)$ & \\
\hline No insurance & $639(11.7 \%)$ & $623(11.4 \%)$ & $1262(11.5 \%)$ & \\
\hline Other & $24(00.4 \%)$ & $14(00.3 \%)$ & $38(00.3 \%)$ & \\
\hline
\end{tabular}

population-based standing orders as an EMR intervention to facilitate uptake of guideline-based recommendations. Our approach could be applied towards other screening tests that are recommended by the USPSTF such as screening blood glucose in obesity or human immunodeficiency virus in adults. Furthermore, EMR databases can be queried for various cohorts of individuals, allowing for scaling of population-based orders to an entire health system coupled with timely treatment and follow-up for those with abnormal results.

The study's applicability is limited to practices that use an electronic medical record system which allow for bulk order placement. Obtaining laboratory testing for entire patient populations without the need for a provider-patient encounter moves panel management to a new frontier. With incentives increasing to encourage population health management, utilizing novel methods such as population-based screening has the potential to rapidly scale up screening and reduce gaps in care cascades throughout medicine.

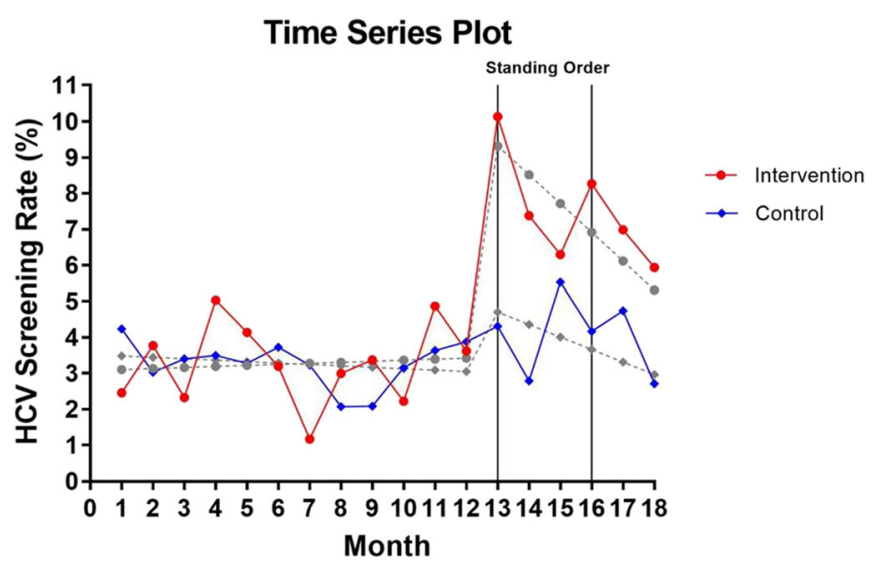

Figure 1 Time series plot.
Jesse O'Shea, MD, MSc ${ }^{1}$

I-Hsin Lin, $\mathrm{PhD}, \mathrm{MPH}^{2}$

Bradley Richards, $M D, M B A^{3}$

${ }^{1}$ Division of Infectious Diseases, Emory University, School of Medicine,

Atlanta, GA, USA

${ }^{2}$ Yale Center for Analytical Sciences, Yale School of Public Health,

New Haven, CT, USA

${ }^{3}$ Department of Internal Medicine, Yale School of Medicine,

New Haven, CT, USA

Corresponding Author: Jesse O'Shea, MD, MSc; Division of Infectious Diseases, Emory University, School of Medicine, Atlanta, GA, USA (e-mail: Jesse.oshea@emory.edu).

\section{REFERENCES}

1. Smith BD, Yartel AK, Krauskopf $\mathbf{K}$, et al. Hepatitis C virus antibody positivity and predictors among previously undiagnosed adult primary care outpatients: cross-sectional analysis of a multisite retrospective cohort study. Clin Infect Dis. 2015;60(8):1145-1152. https://doi.org/10. 1093/cid/civ002.

2. Konerman MA, Thomson M, Gray K, et al. Impact of an electronic health record alert in primary care on increasing hepatitis c screening and curative treatment for baby boomers. Hepatology. 2017;66(6):1805-1813. https://doi.org/10.1002/hep.29362.

3. Gemelas J, Locker R, Rudd S, Prevost C, Reilley B, Leston J. Impact of Screening Implementing HCV Screening of Persons Born 1945-1965: A Primary Care Case Study. J Prim Care Community Health. 2016;7(1):3032. https://doi.org/10.1177/2150131915602020.

4. Brady JE, Liffmann DK, Yartel A, et al. Uptake of hepatitis C screening, characteristics of patients tested, and intervention costs in the BEST-C study. Hepatology. 2017;65(1):44-53. https://doi.org/10.1002/hep.28880.

5. Castrejón M, Chew KW, Javanbakht M, Humphries R, Saab S, Klausner JD. Implementation of a Large System-Wide Hepatitis C Virus Screening and Linkage to Care Program for Baby Boomers. Open Forum Infect Dis. 2017; 4(3): ofx109.

6. Strazzabosco M, Allen JI, Teisberg EO. Value-based care in hepatology. Hepatology. 2017;65(5):1749-55. https://doi.org/10.1002/hep.29042.

Publisher's Note Springer Nature remains neutral with regard to jurisdictional claims in published maps and institutional affiliations. 